\title{
Study on Growth Mechanism of Cu Nanowires and Its Application as Transparent Conducting Electrode
}

\author{
Dedi Mardiansyah ${ }^{1,2}$, Kuwat Triyana ${ }^{1,3}$, and Harsojo ${ }^{1,3, *}$ \\ ${ }^{1}$ Department of Physics, Faculty of Mathematics and Natural Science, Universitas Gadjah Mada, \\ Sekip Utara BLS 21, Yogyakarta 55281, Indonesia \\ ${ }^{2}$ Department of Physics Education, Faculty of Teaching and Education, Universitas Pasir Pengaraian, \\ Jl. Tuanku Tambusai, Rambah, Pasir Pengairan, Rokan Hulu, Riau 28558, Indonesia \\ ${ }^{3}$ Nanomaterials Research Group, Universitas Gadjah Mada, \\ Jl. Kaliurang KM.4 Sekip Utara, Yogyakarta 55281, Indonesia
}

\author{
*Corresponding author: \\ email: harsojougm@ugm.ac.id \\ Received: December 4, 2017 \\ Accepted: April 19, 2018
}

DOI: $10.22146 / \mathrm{ijc} .30985$

\begin{abstract}
Cu}$ nanowires (CuNWs) were synthesized in an aqueous solution at low temperature using ethylenediamine (EDA) as a capping agent and hydrazine as a reducing agent. This study investigated the growth of mechanism CuNWs and fabricated the transparent conducting electrode. For the growth mechanism of CuNWs, the study was conducted with an optical microscope, scanning electron microscopy (SEM), transmission electron microscopy (TEM) and X-ray diffraction (XRD). The performance of the transparent conducting electrode was studied with UV-Vis spectrometer and IV meters. CuNWs growth from Cu nanoparticles (CuNPs) in the solution. Transparent conducting electrode gave a sheet resistance of $48.8 \mathrm{Ohm} / \mathrm{sq}$ and the transmittance of $52.63 \%$. The understanding of the growing mechanism of Cu nanowires is important for the development of CuNWs for alternative application as a transparent conducting electrode.
\end{abstract}

Keywords: Cu nanowires; transparent conducting electrode; growth mechanism

\section{- INTRODUCTION}

In the recent years, research of nanotechnology attracts special attention to produce the effective and efficient materials such as transparent electrodes, organic solar cells, organic light emitting diodes (OLEDs), and sensors [1]. Transparent electrodes play an important role in many modern devices [2]. Therefore, research on the fabricating of transparent conducting is growing. So far, Indium tin oxide (ITO) is the most widely used as a transparent conducting material, because of its high conductivity and transmittance. Unfortunately, ITO is brittle and easy to crack [3-4]. An attractive alternative for the replacement of ITO is silver nanowires [5]. Silver is a metal that has high conductivity and transparency to comparable levels with ITO [6]. Unfortunately, silver and ITO have weaknesses that less in nature, its make more expensive to produce for the application. Therefore, CuNWs have attracted much attention to the replacement of silver and ITO.

Recently, CuNWs has drawn the attention of researchers due the performance is comparable to silver nanowires and ITO [7]. Moreover, Copper is more abundant than silver and indium, making it becomes a cheaper product [8-10]. In many ways, researchers have developed various methods for synthesizing of CuNWs with a simple and effective route [11]. However, the growing mechanism of CuNWs is still not clear. In this work, we reported a detail growth mechanism of CuNWs in the aqueous solution at low temperature. By studying the growth of mechanism, we can control the parameters for producing CuNWs with high aspect ratio as a specific application. 


\section{- EXPERIMENTAL SECTION}

\section{Materials}

Materials used in this research were copper (II) nitrate trihydrate $\left(\mathrm{Cu}\left(\mathrm{NO}_{3}\right)_{2} \cdot 3 \mathrm{H}_{2} \mathrm{O}\right)(99 \%$, Merck), $\mathrm{NaOH}$ (99\%, Merck), ethylenediamine (EDA, Merck) and hydrazine $\left(\mathrm{N}_{2} \mathrm{H}_{4}\right.$, Merck).

\section{Instrumentation}

The characterization of size and morphology of CuNWs were done using scanning electron microscopy (SEM, JEOL JSM-6510) and transmission electron microscopy- selected area electron diffraction (TEMSAED, JEOL JEM 1400). The CuNWs crystal structure was analyzed using X-ray diffraction (XRD, Shimadzu XRD-6000). The optical and electrical properties of the transparent conducting electrode were analyzed using Ultraviolet-Visible (UV-Vis) spectroscopy (Shimadzu, UV-11700) and Current-Voltage (IV) meters (Keithley, SMU-2400), respectively.

\section{Procedure}

\section{Synthesis Cu nanowires}

$\mathrm{Cu}$ nanowires ( $\mathrm{CuNWs}$ ) were synthesized to study the physical and chemical parameters in the process of CuNWs formation by the aqueous method. The parameters are stirring rate, precursor molar ratio, the temperature of the solution, the volume of EDA and volume of hydrazine.

Fig. 1 shows a schematic scheme to synthesis CuNWs. Fig. 1(a) shows the variation of $\mathrm{Cu}\left(\mathrm{NO}_{3}\right)^{2}$ solution $(0.025-0.2 \mathrm{M})$ in the $20 \mathrm{~mL}$ of distilled water. Subsequently, $\mathrm{Cu}\left(\mathrm{NO}_{3}\right)^{2}$ solution was reacted in the $15 \mathrm{M} \mathrm{NaOH}$ solution with stirring rate $(0-1,100 \mathrm{rpm})$ at 60-90 ${ }^{\circ} \mathrm{C}$ (Fig. 1(b)). After $3 \mathrm{~min}$, EDA (0-1.5 mL) and hydrazine $(0-0.13 \mathrm{~mL})$ were injected into the solution (Fig. 1(c)). After $60 \mathrm{~min}, \mathrm{CuNWs}$ can be floated on the top of the solution (Fig. 1(d)). The next step was cooling down the CuNWs solution to room temperature without stirring process for $2 \mathrm{~h}$. The next step is centrifuged 5 times at $10,000 \mathrm{rpm}$ for $10 \mathrm{~min}$. Then, CuNWs would be preserved in alcohol for protection from oxidation.

\section{Fabrication of transparent conducting electrode}

Before the CuNWs solution coating on the substrate, the substrate must be cleaned with alcohol and sonication. After the cleaning process, the CuNWs solution was dropped on the substrate by measuring pipette at $1 \mathrm{~mL}$. CuNWs were controlled by a Mayer rod coating (Fig. 2).

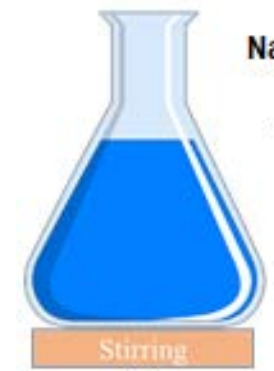

(a)

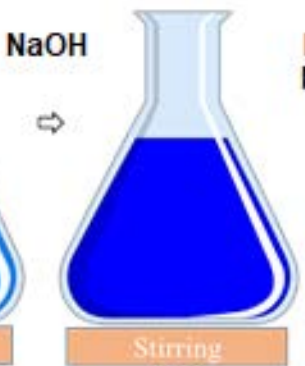

(b)

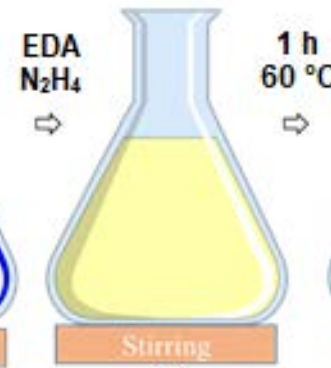

(c)

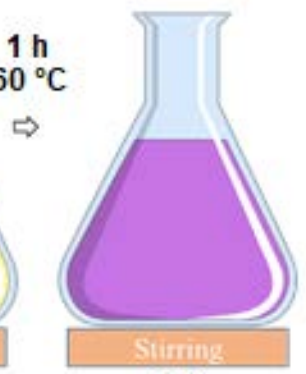

(d)

Fig 1. Synthetic scheme of CuNWs (a) $\mathrm{Cu}\left(\mathrm{NO}_{3}\right)^{2}$ solution, (b) $\mathrm{Cu}\left(\mathrm{NO}_{3}\right)^{2}$ solution $+\mathrm{NaOH},(\mathrm{c}) \mathrm{Cu}\left(\mathrm{NO}_{3}\right)^{2}$ solution + $\mathrm{NaOH}+\mathrm{EDA}+\mathrm{N}_{2} \mathrm{H}_{4}$, (d) CuNWs solution

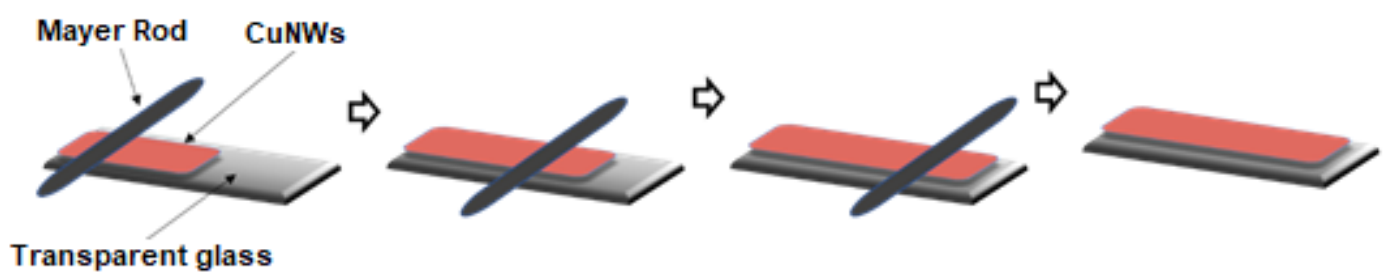

Fig 2. Preparation scheme of the transparent conducting electrode by Mayer Rod method 


\section{- RESULTS AND DISCUSSION}

The role of the materials is necessary for the synthesizing process. Each material affected the growth rate of individual nanowires. The addition of $\mathrm{Cu}\left(\mathrm{NO}_{3}\right)_{2} \cdot 3 \mathrm{H}_{2} \mathrm{O}$ to the solution resulted in a light blue color, indicating the formation of $\mathrm{Cu}\left(\mathrm{NO}_{3}\right)^{2-}$. Furthermore, $\mathrm{NaOH}$ solution was added to $\mathrm{Cu}\left(\mathrm{NO}_{3}\right)^{2}$ solution resulting deep blue color and indicating $\mathrm{Cu}(\mathrm{OH})^{2-}$ (Fig. 3(a)). After 5 min, EDA was injected into the solution resulting $\mathrm{Cu}\left(\mathrm{C}_{2} \mathrm{H}_{8} \mathrm{~N}_{2}\right)^{2-}$. However due to the concentration of $\mathrm{NaOH}$ is excessive, the only resulting $\mathrm{Cu}(\mathrm{OH})^{2-}$. The color changed from deep blue to reddish after addition of $\mathrm{N}_{2} \mathrm{H}_{4}$. The changing of the color from blue to reddish indicated reduction process by $\mathrm{N}_{2} \mathrm{H}_{4}$ (Fig. $3(\mathrm{~b}))$. During the heating process at $60{ }^{\circ} \mathrm{C}$, spherical nanoparticles are initiating to grow. After $60 \mathrm{~min}$, nanowires have grown from spherical nanoparticles and would float on the surface of the solution (Fig. 3(c)).

$$
\begin{aligned}
& 4(\mathrm{Cu}(\mathrm{OH}))^{2-}+\mathrm{N}_{2} \mathrm{H}_{4(\mathrm{aq})} \rightarrow 2 \mathrm{CU}_{2} \mathrm{O}_{(\mathrm{s})}+\mathrm{N}_{2(\mathrm{~g})}+6 \mathrm{H}_{2} \mathrm{O}+8 \mathrm{OH}^{-} \\
& 2 \mathrm{CU}_{2} \mathrm{O}_{(\mathrm{s})}+\mathrm{N}_{2} \mathrm{H}_{4(\mathrm{aq})} \rightarrow 4 \mathrm{CU}_{(\mathrm{s})}+\mathrm{N}_{2}+2 \mathrm{H}_{2} \mathrm{O}
\end{aligned}
$$

The process begins with the formation of $\mathrm{Cu}$ ions (Fig. 4). The formation of $\mathrm{Cu}$ ions begins when $\mathrm{Cu}$ precursor is mixed with $15 \mathrm{M} \mathrm{NaOH}$ solution. The color change to blue indicates the formation of $\mathrm{Cu}^{2+}$. The next process is a reduction. On this process, $\mathrm{Cu}$ ions are neutralized by $\mathrm{N}_{2} \mathrm{H}_{4}$ to $\mathrm{Cu}(0)$ that process called reduction process. After $\mathrm{Cu}$ ions are reduced, EDA was added to the solution for capping process. The capping process is necessary for the formation of CuNWs due to the process determines the shape and diameter of CuNWs. The capping process is the longest process of synthesis nanowire with aqueous solution method. The process began when the first time dropped EDA on the solution until CuNWs form.
Fig. 5 shows images of growing CuNWs that this is a real-time observation of CuNWs growth in solution every $5 \mathrm{~min}$ for $35 \mathrm{~min}$. As shown in Fig. 5, all of the CuNWs grow out of the $\mathrm{Cu}$ nanoparticles (CuNPs) in the solution. CuNPs are a collection of spherical particles $\mathrm{Cu}$. Size of nanoparticles depends on the concentration of $\mathrm{Cu}$ precursor and EDA. When the concentration of $\mathrm{Cu}$ precursor is high, the size of $\mathrm{Cu}$ nanoparticles is bigger [12].

The growth of CuNWs also was determined by the concentration of EDA. When EDA is injecting on the solution, CuNWs begin growth along the axial onedimensional (1-D) [13]. Fig. 5 shows the images during the synthesis process that formation of CuNWs grows from spherical seed nanoparticles. In this research, we probe using an optical microscope (olympus) with magnification 400 times in real time (Fig. 5).

Fig. 5(a-c) show the formation of spherical seed. Spherical seed nanoparticles begin to grow dispersing on the solution (Fig. 5(a)). In this condition, the diameter of spherical seed nanoparticles relatively smaller than other conditions. Fig. 5(b) shows spherical seed nanoparticles beginning to the capping process. Spherical nanoparticles show agglomeration in the solution, which resulted in an increasing diameter of

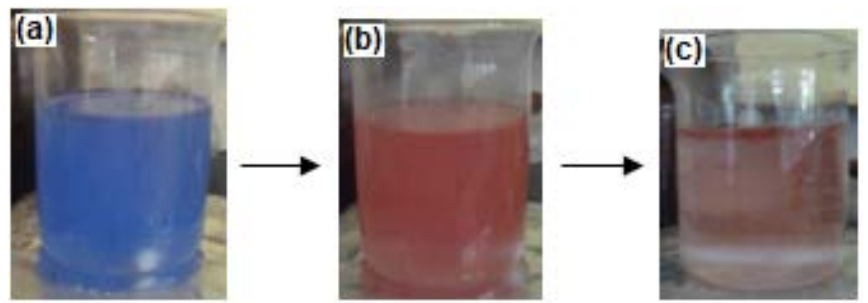

Fig 3. (a) Images of $\mathrm{Cu}$ ion solution, (b) Cu solution after reduction process, (c) CuNWs floating on the surface of the solution

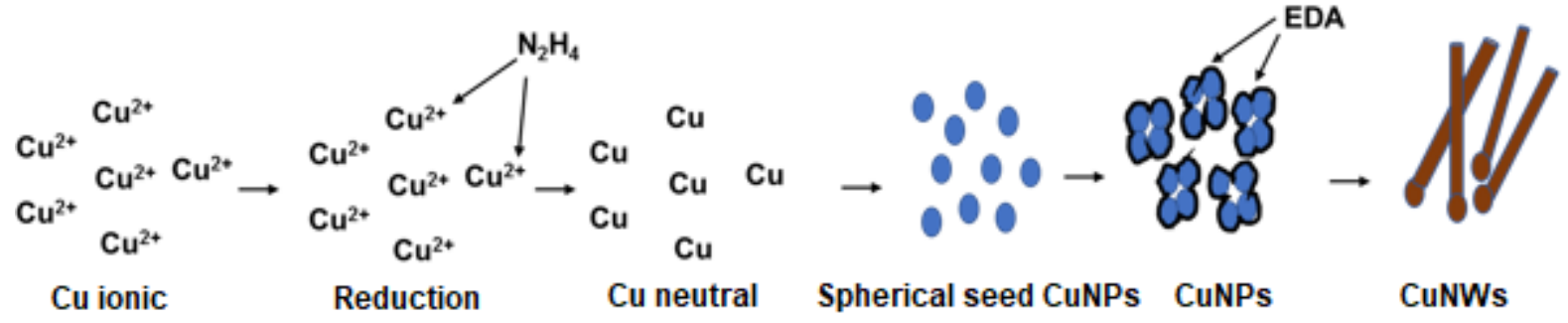

Fig 4. Illustration of the growth mechanism CuNWs on the aqueous solution method 

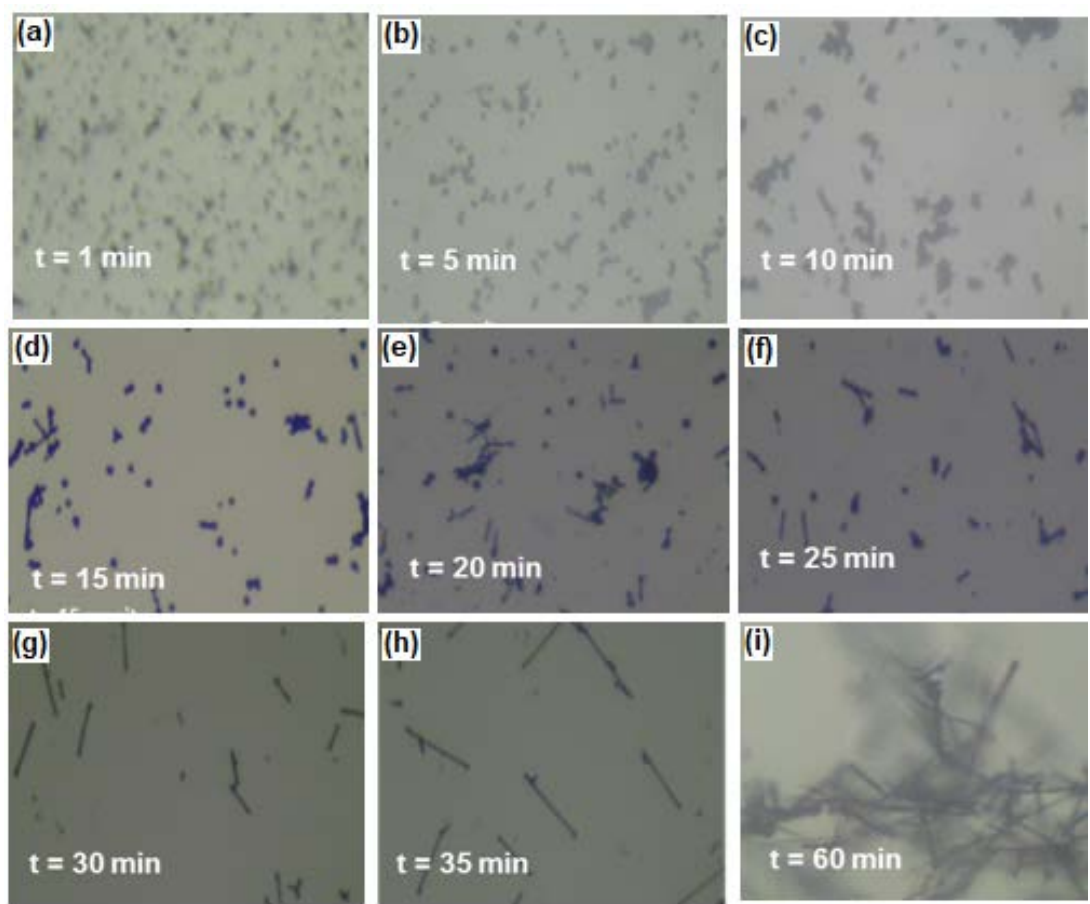

Fig 5. (a-i) The growth of CuNWs was probed by an optic microscope with magnification 400 times

CuNWs. Fig. 5(c) shows the image of the solution after 10 min synthesizing process. The appearance was not change significantly compared with Fig. 5(b), due to only continuing capping process.

The spherical seed nanoparticles begin to grow along the one-dimensional (1-D) after 15 min (Fig. 5(de)). In the condition, CuNWs begin formation although domination of spherical seed nanoparticles. After $25 \mathrm{~min}$ in synthesizing process, short nanowires could be formed (Fig. 5(f)). Fig. 5(g-h) show maximum the growing of CuNWs. On the figures, CuNWs are perfectly formed because the grow of CuNWs are maximum after $35 \mathrm{~min}$. After $35 \mathrm{~min}$, the growing of CuNWs has no significance. Fig. 5(i) shows the image of CuNWs after $60 \mathrm{~min}$. On the image, CuNWs were ready for the next characterizations.

In order to characterize CuNWs, we used X-ray diffraction (XRD) to study about crystallinity of structure CuNWs (Fig. 6(a)). The peaks at $2 \theta=43.7,49.8$ and $74.3^{\circ}$ correspond to the diffractions from the [111], [200] and [220] crystalline planes of fcc Cu (JCPDS \#04-0836). Meanwhile, the rest of the peak $2 \theta=35.8$ appeared [110] plane is indicating of $\mathrm{Cu}_{2} \mathrm{O}$ plane. Fig. 6(b) shows $\mathrm{CuNWs}$ have a uniform diameter and well-dispersed. The diameter and length average of CuNWs are $109 \mathrm{~nm}$ and
$20 \mu \mathrm{m}$, respectively. As shown in Fig. 6(c), spherical nanoparticles were appeared on the end of each nanowire. Spherical nanoparticles are spherical seed in the growing mechanism of CuNWs. The diameter of CuNWs was affected by the diameter of spherical nanoparticles. When the spherical nanoparticles increase in diameter, the diameter of CuNWs becomes increasing.

Fig. 6(d) shows the peak absorbance of CuNWs at $599 \mathrm{~nm}$. The peak may results from the surface plasmon resonance and diameter of CuNWs [14]. Meanwhile, single CuNWs was observed more clearly using TEM in Fig. 6(e). The inset image shows a spherical seed of nanoparticle at the end of the nanowire. It is clear that the wires grew from the spherical nanoparticles. Fig. 6(f) shows a selected area electron diffraction (SAED) pattern of CuNWs. The SAED pattern indicates that CuNWs consist of a single crystalline with the orientation along [110] axis [15]. The SAED pattern is a similarity with the XRD pattern. The diffractions are [111], [200], and [220].

To characterize the electrical and optical properties of CuNWs, the transparent conducting electrode of CuNWs were prepared by Mayer rod method. CuNWs 

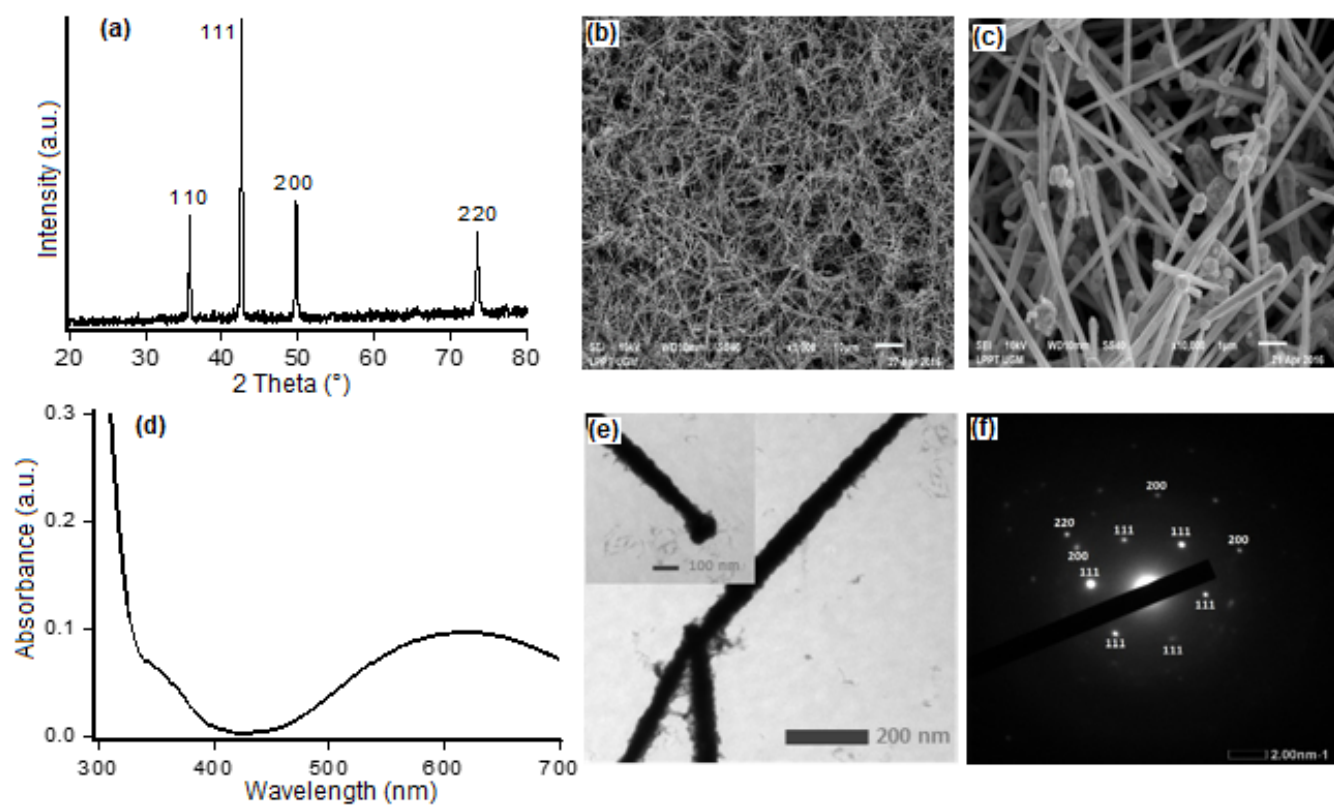

Fig 6. (a) XRD pattern of the CuNWs, (b, c) SEM images of CuNWs, (d) Absorbance spectrum of CuNWs, (e) TEM image of CuNWs, (f) SAED of CuNWs
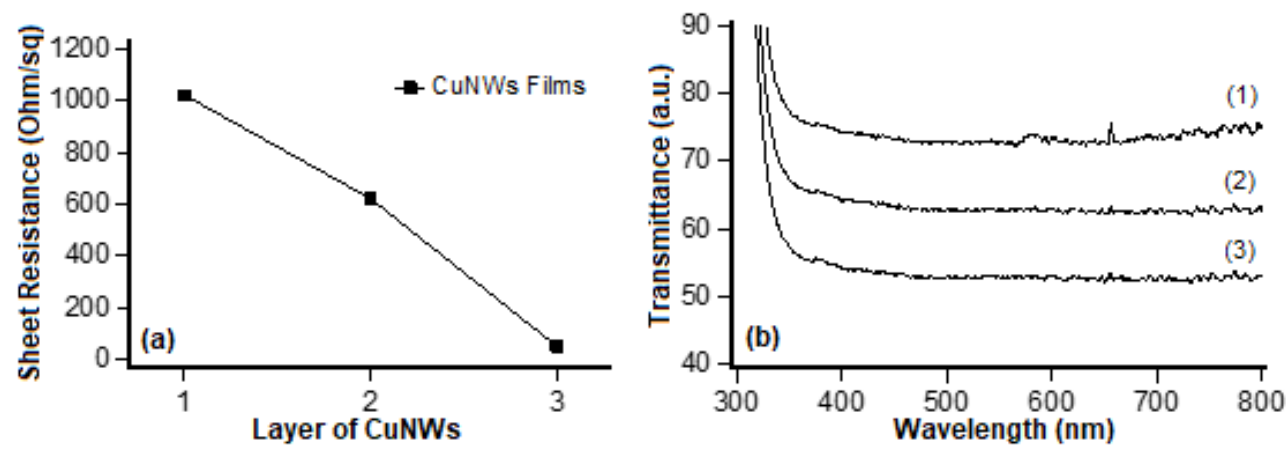

Fig 7. Curves of (a) Sheet resistance versus number of layer CuNWs film, (b) Transmittance versus a number of layer CuNWs

solution was deposited on the glass slides roll-by-roll. The electrical and optical of CuNWs film were measured with a dual-point probe and an UV-Vis spectrophotometer, respectively. Fig. 7(a) shows the decreasing of sheet resistance to a number of layer transparent conducting electrode CuNWs. The sheet resistance of transparent conducting electrode based on a number of the layer that once, twice and three times are 1020.7, 620.3, and 48.8 $\mathrm{Ohm} / \mathrm{sq}$, respectively. While the transmittance of CuNWs film is also decreasing to a number of layer transparent conducting electrode CuNWs. The transmittance of the layer once, twice and three times are 77.2, 62.63, and $52.63 \%$. The number of layer CuNWs films can increase the electrical conductivity, but it decreases the optical transmittance. The above progress clearly shows that CuNWs films are qualified to be an alternative as a transparent conducting electrode.

\section{- CONCLUSION}

The growth of mechanism CuNWs has been successfully studied. The growth of CuNWs begins on the formation of spherical seed CuNPs. Spherical seed CuNPs had formed after the reduced process by $\mathrm{N}_{2} \mathrm{H}_{4} \cdot \mathrm{CuNPs}$ were carried out capping process formation of $\mathrm{CuNW}_{\mathrm{S}}$ by EDA. The EDA is necessary to promote the growth of CuNWs to one-dimensional. Subsequently, the product of CuNWs was coated on the 
substrate for the application as a transparent conducting electrode. The electrical and optical properties confirmed the transparent conducting electrode with a sheet resistance of $1020.7 \mathrm{Ohm} / \mathrm{sq}$ and transmittance of $77.2 \%$.

\section{- ACKNOWLEDGMENTS}

This research was supported by a research grant of "International Research Collaboration and Scientific Publication, Contract No.: 1021/UN1-PIII/LT/DITLIT/2016" by the Directorate General of Resources for Science, Technology and Higher Education, the Republic of Indonesia.

\section{- REFERENCES}

[1] Kim, M.J., Flowers, P.F., Stewart, I.E., Ye, S., Baek, S., Kim, J.J., and Wiley, B.J., 2017, Ethylenediamine promotes $\mathrm{Cu}$ nanowire growth by inhibiting oxidation of $\mathrm{Cu}(111)$, J. Am. Chem. Soc., 139 (1), 277-284.

[2] Sannicolo, T., Lagrange, M., Cabos, A., Celle, C., Simonato, J., and Bellet. D., 2016, Metallic nanowirebased transparent electrodes for next generation flexible devices : A review, Small, 12 (44), 6052-6075.

[3] Mardiansyah, D., Badloe, T., Triyana, K., Mehmood, M.Q., Raeis-Hosseini, N., Lee, Y., Harsojo, Kim, K., and Rho, J., 2018, Effect of Temperature on The Oxidation of $\mathrm{Cu}$ Nanowires and Development of an Easy to Produce, Oxidation-Resistant Transparent Conducting Electrode using a PEDOT:PSS Coating, Sci. Rep., 10639, 1-9.

[4] Zhai, H., Wang, R., Wang, X., Cheng, Y., Shi, L., and Sun, J., 2016, Transparent heaters based on highly stable Cu nanowire films, Nano Res., 9 (12), 39243936.

[5] Liu, Y., Zhang, J., Gao, H., Wang, Y., Liu, Q., Huang, S., Guo, C.F., and Ren, Z., 2017, Capillary-forceinduced cold welding in silver-nanowire-based flexible transparent electrodes, Nano Lett., 17 (2), 1090-1096.

[6] Wang, R., and Ruan, H., 2016, Synthesis of copper nanowires and its application to the flexible transparent electrode, J. Alloys Compd., 656, 936943.
[7] Mardiansyah, D., Triyana, K., and Harsojo, 2016, Effect of precursor molar ratio on the yield of $\mathrm{Cu}$ nanowires synthesized using aqueous solution method, Int. J. Adv. Sci. Eng. Inf. Technol., 6 (4), 447-450.

[8] Chu, H.C., Chang, Y.C., Lin, Y., Chang, S.H., Chang, W.C., Li, G.A., and Tuan, H.Y., 2016, Spraydeposited large-area copper nanowire transparent conductive electrodes and their uses for touch screen applications, ACS Appl. Mater. Interfaces, 8 (20), 13009-13017.

[9] Nam, V., and Lee, D., 2016, Copper nanowires and their applications for flexible, transparent conducting films: A review, Nanomaterials, 6 (3), E47.

[10] Hwang, H., Kim, A., Zhong, Z., Kwon, H., and Jeong, S., 2016, Reducible-shell-derived purecopper-nanowire network and its application to transparent conducting electrodes, Adv. Funct. Mater., 26 (36), 6545-6554.

[11] Huang, W., Li, J., Han, F., Zhang, G., Suna, R., and Wong, C.P., 2017, Controllable synthesis and study on the morphology of copper nanowires, J. Chin. Chem. Soc., 64 (11), 1354-1359.

[12] Mardiansyah, D., Triyana, K., Sosiati, H., and Harsojo, 2016, Synthesis of copper nanorods by aqueous solution method without heating external, AIP Conf. Proc., 1755 (1), 150019.

[13] Tan, M.R., Donnabelle, M., and Balela, L., 2017, Electrochemical investigation of the growth of copper nanowires in the presence of ethylenediamine through mixed potential, $J$. Electrochem. Soc., 164 (7), 386-393.

[14] Harsojo, Puspita, L.A., Mardiansyah, D., Roto, R., and Triyana, K., 2017, The roles of hydrazine and ethylenediamine in wet synthesis of $\mathrm{Cu}$ nanowire, Indones. J. Chem., 17 (1), 43-48.

[15] Rathmell, A.R., Bergin, S.M., Hua, Y.L., Li, Z.Y., and Wiley, B.J., 2010, The growth mechanism of copper nanowires and their properties in flexible, transparent conducting films, Adv. Mater., 22 (32), 3558-3563. 